\title{
Aplicação de hipoclorito de sódio para recuperação de gotejadores entupidos em irrigação com água ferruginosa
}

\author{
José A. A. de Souza ${ }^{1}$, Élio de A. Cordeiro' ${ }^{1}$ Édio L. da Costa ${ }^{2}$
}

\begin{abstract}
RESUMO
O entupimento dos emissores é o maior problema do sistema de irrigação localizada. Geralmente, esta obstrução causa tanto redução quanto aumento da sua vazão, porém sempre se dá diminuição da uniformidade de distribuição de água do sistema, fato que pode ser minimizado pela aplicação de produtos químicos. O objetivo com este trabalho foi avaliar a aplicação de doses de cloro (50, 100 e $150 \mathrm{mg}$ de cloro livre $\mathrm{L}^{-1}$ de água, $\mathrm{T}_{1}, \mathrm{~T}_{2}$ e $\mathrm{T}_{3}$, respectivamente) na recuperação da vazão nominal (QN) de gotejadores Netafin-Ram 17, que apresentavam vazão média (QM) superior à QN, em razão de entupimentos ocorridos em dois anos de irrigação com água contendo $1,7 \mathrm{mg} \mathrm{L}^{-1}$ de ferro total. Avaliou-se a recuperação da QN e a uniformidade de distribuição de água dos gotejadores. A QN dos gotejadores era de 2,3 $\mathrm{L} \mathrm{h}^{-1}$. Foram realizadas quatro aplicações em cada dose. A vazão média dos gotejadores decresceu gradativamente em todas as doses aplicadas com o aumento do número de aplicações. Os melhores resultados foram alcançados na dosagem de $150 \mathrm{mg} \mathrm{L}^{-1}$, na qual se alcançou a vazão nominal.
\end{abstract}

Palavras-chave: obstrução, ferro, uniformidade, gotejamento

\section{Application of sodium hypoclorite for recovery of clogged emitters working with ferruginous water}

\begin{abstract}
Clogging is a serious problem in trickle irrigation. Usually, this obstruction may cause decrease as well as increase of its discharge, but the water distribution uniformity of system always decreases due to clogging problems. These problems can be reduced by application of chlorine and acids. This work aimed to evaluate application of three concentrations (treatments) of sodium hypoclorite (50, 100 and $150 \mathrm{mg} \mathrm{L}^{-1}$ of free chlorine, $\mathrm{T}_{1}, \mathrm{~T}_{2}$ and $\mathrm{T}_{3}$, respectively) with four applications in order to recover Netafin-Ram 17 emitters that presented average discharge greater than the nominal one, due to clogging caused by irrigation with water presenting $1.7 \mathrm{mg} \mathrm{L}^{-1}$ of total iron during two years. The recovery of nominal discharge and the water distribution uniformity of the emitters were evaluated. The emitter nominal discharge was $2.3 \mathrm{~L} \mathrm{~h}{ }^{-1}$. The mean discharge decreased gradually in all the concentrations with the increase in number of applications. The best results were obtained in the concentrations of $150 \mathrm{mg} \mathrm{L}^{-1}$, in which the nominal flow was attained.
\end{abstract}

Key words: obstruction, iron, uniformity, drip irrigation

${ }^{1}$ UFV, CEP 36571-000, Viçosa, MG. Fone: (31)3899-1939, E-mail: albertojanauba@yahoo.com.br; ${ }^{1}$ cordeiro@vicosa.ufv.br;

2 Epamig, E-mail: ediocosta@hotmail.com. 
José A. A. de Souza et al.

\section{INTRODUÇÃO}

Obstrução dos emissores é o maior impasse do sistema de irrigação localizada e a maior causa na variação de vazão dentro do sistema, pois mesmo uma pequena porcentagem de emissores entupidos pode resultar em grande redução na uniformidade de aplicação de água e, como conseqüência, danos às plantas (Nakayama \& Bucks, 1981).

Esses entupimentos se devem principalmente à baixa velocidade da água na passagem pelo emissor e ao seu pequeno diâmetro, em especial os gotejadores, que são obstruídos facilmente por partículas minerais ou substâncias orgânicas, alterando a vazão dos emissores (Pizarro, 1990).

As obstruções dos emissores podem ser causadas por agentes físicos, químicos e biológicos. A determinação da causa dessas obstruções pode ser complexa, pelo fato dos vários agentes na água poderem interagir entre si, agravando o problema (Ravina et al., 1992).

Na região Sudeste do Brasil freqüentemente se encontram águas que apresentam elevados teores de ferro total, elemento este que pode provocar sérios problemas de entupimento, sobretudo quando presente em forma reduzida, podendo precipitar-se no interior das tubulações quando oxidado favorecendo, ainda, o desenvolvimento de ferrobactérias.

Bucks et al. (1979) estabeleceram que, para ser utilizada sem restrição na irrigação, a água deve apresentar concentração de ferro menor que $0,1 \mathrm{mg} \mathrm{L}^{-1}$ e que a utilização de águas com teor de ferro maior que $1,5 \mathrm{mg} \mathrm{L}^{-1}$ em sistemas de irrigação por gotejamento, possui severas restrições, de vez que apresenta alto risco de entupimento de gotejadores; No entanto, Ayers \& Westcot (1999) afirmam que, quando os custos dos filtros são incluídos, o valor máximo prático é de 2,0 $\mathrm{mg} \mathrm{L}^{-1}$.

A recuperação de emissores entupidos por microrganismos é difícil. Quando os gotejadores são desmontáveis, podem ser desobstruídos manualmente, porém o custo dessa operação pode ser inviável. O controle das obstruções por meio de agentes químicos e biológicos requer injeção de produtos químicos no sistema de gotejamento. O cloro e os ácidos são os produtos mais utilizados, tanto como medida preventiva quanto para recuperar emissores obstruídos (James, 1988).

Dentre as formas comerciais de cloro, a mais utilizada é o hipoclorito de sódio $(\mathrm{NaOCl})$, cuja aplicação na água de irrigação resulta em formação de ácido hipocloroso $(\mathrm{HOCl})$ e íons hidroxila $\left(\mathrm{OH}^{-}\right)$, uma reação que eleva o $\mathrm{pH}$ da água. Segundo Clark \& Smajstrla (1999), o ácido hipocloroso é o agente efetivo que controla o crescimento de bactérias. A quantidade de $\mathrm{HOCl}$ que estará presente na solução, dependerá do $\mathrm{pH}$. Em pH igual a 8 , somente cerca de $22 \%$ do cloro injetado estarão na forma ativa $\mathrm{HOCl}$, em $\mathrm{pH}$ igual a 7 , haverá cerca de $73 \%$ e, em pH igual a 6 , cerca de $96 \%$ do cloro estarão na forma ativa. Portanto, se o pH da água de irrigação for alto, deve-se aplicar ácido antes do cloro, para baixá-lo, mantendo-o na faixa entre 5,0 e 6,0.

Tem-se aplicado cloração de $100 \mathrm{mg} \mathrm{L}^{-1}$ a $1.000 \mathrm{mg} \mathrm{L}^{-1}$, porém tal tratamento pode causar prejuízo à cultura e ao equipamento. Com gotejadores parcialmente entupidos,
Pizarro (1990) recomenda a aplicação de 250 a $500 \mathrm{mg} \mathrm{L}^{-1}$ de cloro durante $12 \mathrm{~h}$, seguida de uma lavagem com água em alta pressão.

Nakayama et al. (1977) recuperaram emissores obstruídos por lodo biológico que apresentavam, antes do tratamento, vazão média inferior a $50 \%$ da vazão nominal, com aplicação de $100 \mathrm{mg} \mathrm{L}^{-1}$ de cloro livre por 24 h e adição de ácido sulfúrico para baixar o pH para 2. Após o tratamento, a vazão média ficou entre 90 e $95 \%$ da vazão nominal.

Outro tratamento que tem apresentado bons resultados na recuperação da vazão nominal do gotejador, é a aplicação, durante uma hora, de 100 a $150 \mathrm{mg} \mathrm{L}^{-1}$ de cloro livre associado ao ácido fosfórico, para manter o $\mathrm{pH}$ da solução entre 5 e 6. Para esse tratamento, entretanto, são necessárias, em geral, de três a cinco aplicações de uma hora cada. Segundo Nakayama et al. (1977), deve-se aumentar 10 a 20\% na concentração de cloro livre desejada, visto que parte do cloro reage com substâncias contidas na água de irrigação.

Geralmente, as obstruções causam diminuição da vazão dos emissores; por outro lado, existem alguns modelos de emissores nos quais ocorre o oposto. Ravina et al. (1992), trabalharam com emissores autocompensantes e não autocompensantes e observaram aumento da vazão no início do processo de entupimento, em ambos os tipos. Cordeiro (2002) e Souza (2002) constataram aumento da vazão de gotejadores Netafim RAM 17 após dois anos de operação, o que alterou a uniformidade de distribuição de água do sistema e, conseqüentemente, reduziu a eficiência do uso da água. Este mesmo comportamento foi observado por Resende et al. (2000), com os gotejadores Netafim RAM e Dripline, no qual, o aumento da vazão, pode estar associado ao primeiro estágio de acumulação de material dentro do emissor, o que pode alterar o regime do escoamento. Em modelos autolimpantes, o mecanismo de auto-limpeza é projetado para expelir qualquer partícula que possa causar o entupimento, pelo incremento da pressão diferencial, que faz com que o diafragma aumente, momentaneamente, o volume do corte transversal da saída de água para expulsar a sujeira do sistema. Como a mucilagem formada por ferrobactérias se adere fortemente às paredes internas dos gotejadores, este aumento de volume pode ser contínuo, o que também explicaria o aumento de vazão.

O objetivo, com este trabalho, foi avaliar o efeito de doses de hipoclorito de sódio e diferentes números de aplicações na recuperação da vazão nominal dos gotejadores e na melhoria da uniformidade de distribuição de água.

\section{MATERIAL E MÉTODOS}

O experimento foi realizado no Laboratório de Hidráulica do Departamento de Engenharia Agrícola da Universidade Federal de Viçosa, localizado no município de Viçosa, MG, de março a maio de 2002. Utilizou-se água da lagoa próxima ao Laboratório, com $\mathrm{pH} \mathrm{6,7} \mathrm{e} \mathrm{teor} \mathrm{de} \mathrm{ferro} \mathrm{inferior} \mathrm{a}$ $0,2 \mathrm{mg} \mathrm{L}^{-1}$.

Instalaram-se 12 linhas laterais, cada uma com 16 gotejadores espaçados 0,75 m (Figura 1), marca Netafin, modelo 
Ram 17, autocompensante que, segundo o fabricante, apresenta vazão nominal de $2,3 \mathrm{~L} \mathrm{~h}^{-1}$, para pressão de serviço variando entre 49,05 e 392,40 kPa. Essas linhas foram retiradas do sistema de irrigação da Fazenda Vista Alegre, localizada no município de Jaboticatubas, MG, latitude $19^{\circ} 34^{\prime} \mathrm{S}$ e longitude $43^{\circ} 52^{\prime} \mathrm{W}$, com dois anos de uso, operando com água contendo $1,7 \mathrm{mg} \mathrm{L}^{-1}$ de ferro total. Os gotejadores apresentavam vazão média superior à vazão nominal do modelo, enquanto a pressão média de operação na propriedade variava de 70 a $350 \mathrm{kPa}$.

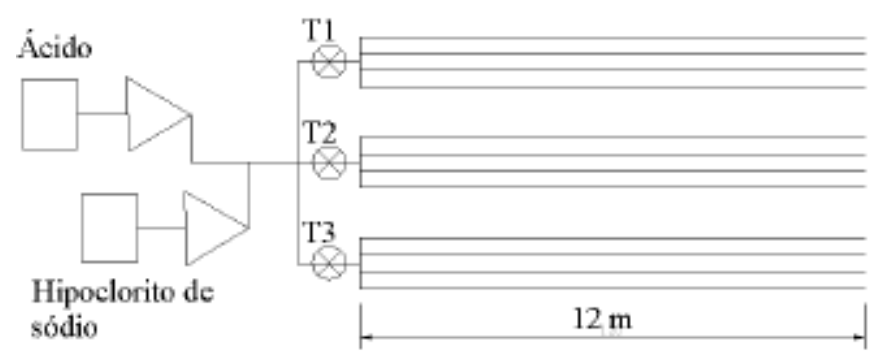

Caixa d'água

Figura 1. Esquema do sistema de distribuição de água para o estudo sobre o efeito de diferentes números de aplicação de hipoclorito de sódio, em que T1, T2 e T3 são os tratamentos com as doses de 50, 100 e $150 \mathrm{mg} \mathrm{L}^{-1}$ de cloro livre, respectivamente.

O produto utilizado no tratamento químico foi o hipoclorito de sódio ( $12 \%$ de cloro livre), nas doses de 50, 100 e 150 $\mathrm{mg} \mathrm{L}^{-1}$ de cloro livre, chamados tratamentos $\mathrm{T}_{1}, \mathrm{~T}_{2}$ e $\mathrm{T}_{3}$, respectivamente. Para cada dose foram realizadas quatro aplicações, ou seja, 5 tratamentos correspondentes a 0, 1, 2, 3 e 4 aplicações. $\mathrm{O}$ experimento foi desenvolvido em esquema fatorial para estudar o efeito de doses de hipoclorito de sódio (50, 100 e $\left.150 \mathrm{mg} \mathrm{L}^{-1}\right)$ com cinco aplicações $(0,1,2,3$ e 4) na recuperação da vazão nominal de gotejadores e na melhoria da uniformidade de distribuição da água. O delineamento utilizado foi inteiramente casualizado em quatro repetições. Aplicou-se o teste de Tukey para comparar as médias. Para permitir melhor eficiência do poder bactericida do ácido hipocloroso, utilizou-se ácido fosfórico para baixar o $\mathrm{pH}$ para valores próximos a 5,0. Em relação à quantidade de ácido fosfórico utilizada, obedeceu-se a titulação prévia, ou seja, 0,05 $\mathrm{mL} \mathrm{L}^{-1}$ de água.

A aplicação de cloro se deu durante o período de uma hora, em todas as aplicações e em todos os tratamentos, com pressão de serviço variando entre 230 e $240 \mathrm{kPa}$. Após cada aplicação, o sistema ficou em repouso 24 h e, após este período, foi religado com água limpa, mantendo-se os finais de linha abertos, a fim de permitir a limpeza das laterais. Adotou-se o mesmo procedimento para todas as aplicações.

Os produtos foram diluídos em água em diferentes recipientes e injetados com o auxílio de duas motobombas, em que o hipoclorito foi injetado em um ponto posterior ao ponto de injeção do ácido.

Para a avaliação do sistema, coletaram-se as vazões de todos os gotejadores durante $3 \mathrm{~min}$, antes dos tratamentos e $24 \mathrm{~h}$ após cada aplicação dos produtos, para determinar a vazão média, o coeficiente de uniformidade de distribuição (CUD) e o coeficiente de variação (CV).

O CUD foi determinado aplicando-se a metodologia proposta por Keller \& Karmeli (1975). Segundo Lopes et al. (1992), atualmente o uso deste coeficiente é mais freqüente, pois ele compara a média de $25 \%$ das observações de valores mais baixos com a média total.

Após a aplicação dos produtos, os três sistemas foram avaliados nos mesmos moldes anteriores, aplicando-se apenas água da lagoa, sob quatro diferentes pressões de serviço: $78,5,157,0,235,4$ e $319,9 \mathrm{kPa}$, com o objetivo de avaliar o comportamento da membrana de autocompensação dos gotejadores, após a aplicação dos produtos químicos.

\section{RESULTADOS E DISCUSSÃO}

Realizou-se a análise estatística para as variáveis: vazão (Q), CUD e o CV, em função dos diferentes tratamentos aplicados.

Pela análise de variância, obtiveram-se os seguintes resultados: para a variável Q e CV, encontrou-se diferença significativa a $1 \%$ de probabilidade pelo teste $\mathrm{F}$, quanto ao número de aplicações e as doses de hipoclorito; em relação à variável CUD verificou-se diferença significativa a $1 \%$ de probabilidade, pelo teste $\mathrm{F}$, quanto ao número de aplicações.

Na comparação das médias pelo teste Tukey a $5 \%$ de probabilidade, verificou-se efeito significativo do número de aplicações sobre as médias das variáveis Q, CV e CUD. Quanto às doses de hipoclorito não houve diferença significativa, a $5 \%$ de probabilidade, entre as médias das variáveis estudadas.

Os resultados foram analisados por doses de hipoclorito aplicada.

\section{Dose de $50 \mathrm{mg} \mathrm{L}^{-1}$}

Aplicando-se o teste Tukey sobre as médias da variável Q em função do número de aplicações realizadas observase, a partir da segunda aplicação, diferença entre as médias, com o melhor resultado após quatro aplicações (Tabela 1); observa-se que a vazão média se aproximou da nominal $\left(2,3 \mathrm{~L} \mathrm{~h}^{-1}\right)$, gradativamente, após cada aplicação, mas não a atingiu; a variável $\mathrm{CV}$ apresentou diferença entre a testemunha, aplicação zero, somente após a quarta aplicação; para a variável CUD não houve diferença entre as

Tabela 1. Valores médios de vazão, CV e CUD para a dose de $50 \mathrm{mg} \mathrm{L}^{-1}$ e testes de média, respectivamente.

\begin{tabular}{cccc}
\hline Aplicação & ${\text { Vazão*(Q) } \mathbf{L} \mathbf{h}^{-1}}$ & CV $^{*}$ & CUD* (\%) $^{*}$ \\
0 & $2,98 \mathrm{a}$ & $0,22 \mathrm{a}$ & $82,79 \mathrm{a}$ \\
1 & $2,84 \mathrm{ab}$ & $0,16 \mathrm{ab}$ & $85,96 \mathrm{a}$ \\
2 & $2,77 \mathrm{bc}$ & $0,15 \mathrm{ab}$ & $87,60 \mathrm{a}$ \\
3 & $2,58 \mathrm{~cd}$ & $0,16 \mathrm{ab}$ & $85,53 \mathrm{a}$ \\
4 & $2,55 \mathrm{~d}$ & $0,13 \mathrm{~b}$ & $89,14 \mathrm{a}$ \\
\hline
\end{tabular}

* Média com a mesma letra na coluna não indica diferença significativa pelo teste Tukey, a 1\% de probabilidade 
médias. No entanto, o CUD já é um coeficiente estatístico da variação da vazão e não deve ser analisado separadamente, isto é, sem a vazão. Tais resultados indicam clara tendência de recuperação da vazão nominal e melhoria da uniformidade de aplicação de água, porém seriam necessárias mais aplicações para se atingir a vazão nominal, com prováveis melhorias, também no $\mathrm{CV}$ e no CUD.

\section{Dose de $100 \mathrm{mg} \mathrm{L}^{-1}$}

De acordo com o teste Tukey, aplicado sobre as médias da variável Q em função do número de aplicações realizadas, observa-se o mesmo comportamento da dose de $50 \mathrm{mg} \mathrm{L}^{-1}$ (Tabela 2). Para a variável CV e CUD, não ocorreu diferença entre as médias, observando-se que a vazão média se aproximou da nominal $\left(2,3 \mathrm{~L} \mathrm{~h}^{-1}\right)$, gradativamente, após cada aplicação, mais eficientemente que na dose de $50 \mathrm{mg} \mathrm{L}^{-1}$, mas também não a atingiu, embora tenha atingido um valor mais próximo da mesma. Considerando-se os resultados observados para CV e para CUD que, embora não tenham mostrado diferença significativa, observou-se uma tendência de redução gradativa no $\mathrm{CV}$ e de aumento gradativo no CUD. Considerando-se tais resultados nota-se que a dose de $100 \mathrm{mg} \mathrm{L}^{-1}$ foi eficiente na recuperação da vazão nominal, mas há necessidade de mais aplicações.

Tabela 2. Valores médios de vazão, CV e CUD para a dose de $100 \mathrm{mg} \mathrm{L}^{-1}$ e respectivos testes de média

\begin{tabular}{cccc}
\hline Aplicação & Vazão* (Q) L h $^{-1}$ & CV* $^{*}$ & CUD* (\%) $^{*}$ \\
0 & $3,02 \mathrm{a}$ & $0,16 \mathrm{a}$ & $80,67 \mathrm{a}$ \\
1 & $2,93 \mathrm{ab}$ & $0,14 \mathrm{a}$ & $84,89 \mathrm{a}$ \\
2 & $2,79 \mathrm{~b}$ & $0,13 \mathrm{a}$ & $87,45 \mathrm{a}$ \\
3 & $2,59 \mathrm{c}$ & $0,12 \mathrm{a}$ & $86,49 \mathrm{a}$ \\
4 & $2,49 \mathrm{c}$ & $0,11 \mathrm{a}$ & $86,60 \mathrm{a}$ \\
\hline
\end{tabular}

* Média com a mesma letra entre colunas não indica diferença significativa pelo teste Tukey, a 1\% de probabilidade

\section{Dose de $150 \mathrm{mg} \mathrm{L}^{-1}$}

Com os resultados do teste de Tukey aplicado sobre as médias da variável $\mathrm{Q}$, em função do número de aplicações realizadas, observou-se diferença, em relação à testemunha, a partir da primeira aplicação (Tabela 3 ). A vazão decresceu gradualmente com o aumento do número de aplicações, alcançando a vazão nominal após a quarta aplicação. Para a variável $\mathrm{CV}$, nota-se diferença a partir da terceira aplicação,

Tabela 3. Valores médios de vazão, CV e CUD para a dose de $150 \mathrm{mg} \mathrm{L}^{-1}$ e respectivos testes de média.

\begin{tabular}{cccc}
\hline Aplicação & ${\text { Vazão* }(\mathbf{Q}) \mathbf{L ~ h}^{-1}}$ & CV * $^{*}$ & CUD* (\%) $^{*}$ \\
0 & $2,95 \mathrm{a}$ & $0,19 \mathrm{a}$ & $77,92 \mathrm{a}$ \\
1 & $2,63 \mathrm{~b}$ & $0,16 \mathrm{ab}$ & $83,82 \mathrm{ab}$ \\
2 & $2,66 \mathrm{bc}$ & $0,13 \mathrm{abc}$ & $87,81 \mathrm{~b}$ \\
3 & $2,47 \mathrm{~cd}$ & $0,11 \mathrm{bc}$ & $89,80 \mathrm{~b}$ \\
4 & $2,31 \mathrm{~d}$ & $0,07 \mathrm{c}$ & $91,94 \mathrm{~b}$ \\
\hline
\end{tabular}

* Média com a mesma letra entre colunas não indica diferença significativa pelo teste Tukey, a 1\% de probabilidade com o melhor resultado na quarta aplicação, enquanto que na variável CUD, houve diferença a partir da segunda aplicação em relação à testemunha (Tabela 3 ). Os resultados mostram que, ao contrário dos tratamentos 1 e 2, o tratamento 3 foi eficiente na recuperação da vazão nominal e na melhoria substancial da uniformidade de aplicação de água pelo sistema, com quatro aplicações.

A vazão obtida na dose 3, após a quarta aplicação, foi igual à nominal. A tendência dos resultados confirma a hipótese de que o gotejador avaliado, ao contrário da maioria dos modelos de gotejadores, aumenta a vazão à medida que mostra problemas de entupimento e este aumento de vazão não é causado por desgaste da membrana de autocompensação pois, se o fosse, a aplicação desses tratamentos não seria capaz de recuperar a vazão nominal. Os resultados são condizentes com os encontrados por Cordeiro (2002), que observou este mesmo comportamento em gotejadores RAM 17, em pesquisa de laboratório, e por Souza (2002), que notou o mesmo comportamento com esse gotejador, em condições de campo.

A Tabela 4 apresenta as percentagens de gotejadores que se encontram na faixa de 90 a $110 \%$ da vazão nominal, em função dos tratamentos e do número de aplicações. Analisando-se esta faixa de vazão para as doses de 50, 100 e $150 \mathrm{mg} \mathrm{L}^{-1}$, verifica-se que antes da primeira aplicação apenas 19,13 e $14 \%$ dos gotejadores, respectivamente, se encontravam nessa faixa de vazão. Com três aplicações, notase que em torno de $50 \%$ dos gotejadores, ou mais, se encontravam na faixa de 90 a $110 \%$ da vazão nominal. Após a quarta aplicação, 66, 55 e $89 \%$ dos gotejadores, respectivamente, se encontravam na faixa de 90 a $110 \%$ da vazão nominal. Ainda sob esse ponto de vista, o tratamento 3 foi superior aos outros dois porém, considerando-se a tendência geral, mais aplicações nos tratamentos com doses inferiores podem atingir os mesmos resultados, o que merece ser investigado, considerando-se o custo e o risco de danos causados à membrana de autocompensação, devido à aplicação de doses elevadas de hipoclorito de sódio, para se definir a melhor opção.

Tabela 4. Porcentagem de gotejadores recuperados considerando-se uma faixa de 90 a $110 \%$ da vazão nominal

\begin{tabular}{cccc}
\hline Aplicação & $\mathbf{5 0 ~} \mathbf{~ g ~ L}^{-1}$ & $\mathbf{1 0 0 ~} \mathbf{~ g ~ L}^{-1}$ & $\mathbf{1 5 0} \mathbf{~ m ~ L}^{-1}$ \\
0 & 19 & 13 & 14 \\
1a & 16 & 17 & 44 \\
2a & 30 & 14 & 38 \\
3a & 52 & 45 & 72 \\
4a & 66 & 55 & 89 \\
\hline
\end{tabular}

A Figura 2 apresenta a relação entre a vazão média e o número de aplicações de hipoclorito de sódio nas diferentes doses do produto.

Após a aplicação dos tratamentos, os sistemas foram avaliados com quatro diferentes pressões de funcionamento, todas dentro da faixa recomendada para o modelo, a fim de se estimar possíveis danos provocados pela utilização de produtos químicos à membrana do gotejador, responsável pelo sistema 

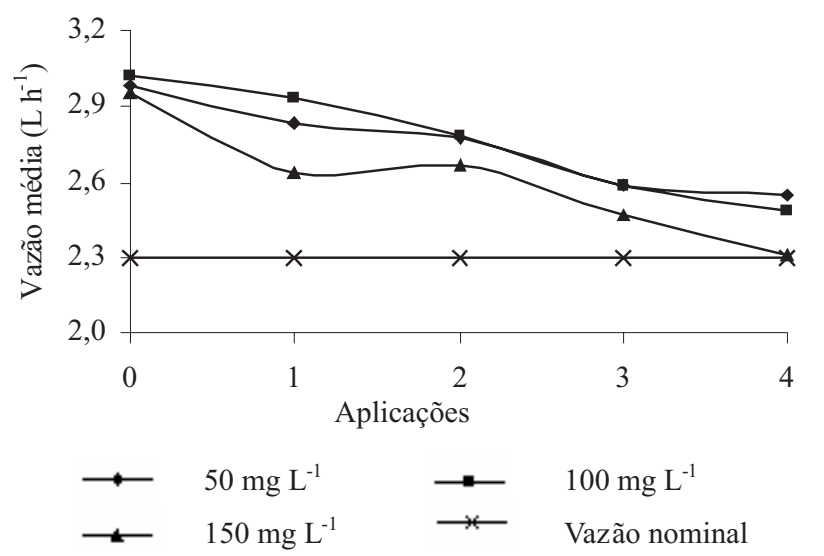

Figura 2. Comportamento da vazão média em relação ao número de aplicações de hipoclorito de sódio à pressão de $235 \mathrm{kPa}$ nas diferentes doses do produto comparativamente à vazão nominal.

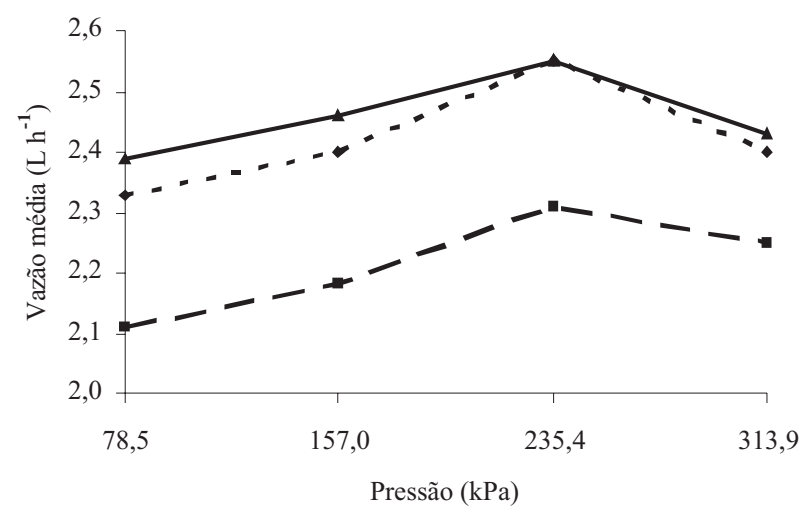

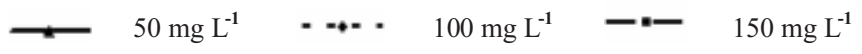

Figura 3. Variação da vazão média em razão de diferentes pressões de funcionamento, nos três tratamentos.

de compensação de vazão. A Figura 3 indica que o comportamento das curvas vazão versus pressão para os tratamentos $1 \mathrm{e}$ 2, apresenta a mesma tendência, com todas as vazões acima da vazão nominal e com variações pequenas, indicando que, provavelmente, não ocorreu dano algum no sistema de compensação; no tratamento 3 as vazões ficaram muito abaixo da vazão nominal nas pressões abaixo de $200 \mathrm{kPa}$ e com pequena variação a partir desta pressão, fato que pode indicar algum possível dano à membrana de compensação, o que é condizente com Nakayama et al. (1977), que afirmam que doses superiores a $100 \mathrm{mg} \mathrm{L}^{-1}$ podem causar este tipo de dano mas, para se afirmar que isto tenha ocorrido, é conveniente uma avaliação com este objetivo tendo como testemunha, gotejadores novos.

\section{CONCLUSÕES}

1. A vazão média dos gotejadores decresceu gradativamente em todas as doses aplicadas com o aumento do número de aplicações.

2. Os melhores resultados foram obtidos com a dose de hipoclorito de $150 \mathrm{mg} \mathrm{L}^{-1}$ em quatro aplicações.

\section{LITERATURA CITADA}

Ayers, R. S.; Westcot, D. W. A qualidade da água na agricultura. Campina Grande: UFPB, 1999. 153p.

Bucks, D. A.; Nakayama, F. S.; Gilbert, R. G. Trickle irrigation water quality and preventive maintenance. Agricultural Water Management, Amsterdam, v.2, n.2, p.149-162. 1979.

Clark, G. A.; Smajstrla, A. G. Treating irrigation systems with chlorine. Cooperative Extension Service. IFAS. University of Florida. 1999. 6p. Circular 1039

Cordeiro, E. A. Influência do tratamento de água ferruginosa no desempenho de sistema de irrigação por gotejamento. Viçosa: UFV, 2002. 92p. Dissertação Mestrado

James, L. G. Principles of farm irrigation system design. Washington State University, New York: John Wiley \& Sons, 1988. 543p.

Keller, J.; Karmeli, D. Trickle irrigation design. Glendora: Rain Bird Sprinkler Manufacturing, 1975. 133p.

Lópes, J. R.; Abreu, J. M. H.; Regalado, A. P.; Hernández, J. F. G. Riego localizado. Madrid: Ed Mundi-Prensa, 1992. 405p.

Nakayama, F. S.; Bucks, D. A. Emitter clogging effects on trickle irrigation uniformity. Transactions of the ASAE, St. Joseph, v.24, n.4, p.77-80, 1981.

Nakayama, F. S.; Bucks, D. A.; French, O.F. Reclaiming partially clogged trickle emitters. Transactions of the ASAE, St. Joseph, v.20 n.2, p.278-280, 1977.

Pizarro, F. Riegos localizados de alta frecuencia. Madrid, Ed: Mundi-Prensa, 2.ed. 1990. 471p.

Ravina, I.; Paz, E.; Sofer, Z.; Marcu, A.; Shisha, A.; Sagi, G. Control of emitter clogging in drip irrigation with reclaimed wastewater. Irrigation Science. New York, v.13, n.3, p.129139. 1992.

Resende, S. R.; Coelho, D. R.; Piedade, S. M. S. Suscetibilidade de gotejadores ao entupimento de causa biológica. Revista Brasileira de Engenharia Agrícola e Ambiental, Campina Grande, v.4, n.3, p.368-375, 2000.

Souza, J. A. A. Desempenho de sistema de irrigação por gotejamento e eficiência da insetigação com imidacloprid no controle do bicho-mineiro (Perileucoptera coffeella) no cafeeiro. Viçosa: UFV, 2002. 47p. Dissertação Mestrado. 